\title{
Modeling methodology and fault simulation of distribution networks integrated with inverter-based DG
}

\author{
Longchang Wang, Houlei Gao* and Guibin Zou
}

\begin{abstract}
The increasing penetration of inverter-based distributed generations (DGs) significantly affects the fault characteristics of distribution networks. Fault analysis is a keystone for suitable protection scheme design. This paper presents the modelling methodology for distribution networks with inverter-based DGs and performs fault simulation based on the model. Firstly, a single inverter-based DG model based on the cascaded control structure is developed. Secondly, a simulation model of distribution network with two inverter-based DGs is established. Then, different fault simulations are performed based on the Real Time Digital Simulator (RTDS). Theoretical analyses are conducted to justify the simulation results, including the equivalent circuit of distribution networks with inverter-based DGs and the solution method for loop currents.
\end{abstract}

Keywords: Distribution network, Inverter-based distributed generation (DG), Simulation model, Fault analysis, Real time digital Simulator (RTDS)

\section{Introduction}

In recent years, different kinds of distributed generation (DG) are being connected in distribution networks, such as wind generation and photovoltaic (PV) generation. A great number of power electronic devices are connected to distribution networks due to the integration of inverter-based DGs. Therefore, compared with traditional distribution network, planning and design, control and protection, simulation and analysis for distribution networks with inverter-based DGs are more complicated. This has motivated a considerable number of studies [1-5].

Simulation model plays an important role in the research of power system. As a real-time simulation tool designed for power system, Real-Time Digital Simulator (RTDS) are widely used for power system simulation and analysis [6-9]. One important advantage of RTDS is that it can interface electrical and control signal with physical devices and achieve hardware-in-loop simulation. Thus, the simulation

\footnotetext{
* Correspondence: houleig@sdu.edu.cn

School of Electrical Engineering, Shandong University, Jinan, China
}

models based on RTDS can be used to test real equipments.

Fault characteristics of distribution networks with DGs are quite different from traditional distribution networks. How to model DG under fault conditions is a prerequisite for fault analysis of the distribution networks with DGs. Researchers have put forward different equivalent models of inverter-based DG to analyze their fault characteristics, such as the current source with a parallel changeable impedance [10], the voltage source with a series changeable impedance [11], and the current source controlled by positive sequence voltage at common coupling point (PCC) [12]. In the previous researches, their simulation models contain only one DG. However, in reality, there may be several DGs placed in different locations.

In this paper, single inverter-based DG is modeled firstly based on RTDS. Then, a simulation model for a distribution network with two inverter-based DGs is developed. After that, fault simulations are performed using the simulation model and the results are analyzed briefly. Theoretical analyses are conducted to justify the correctness of simulation results and the 


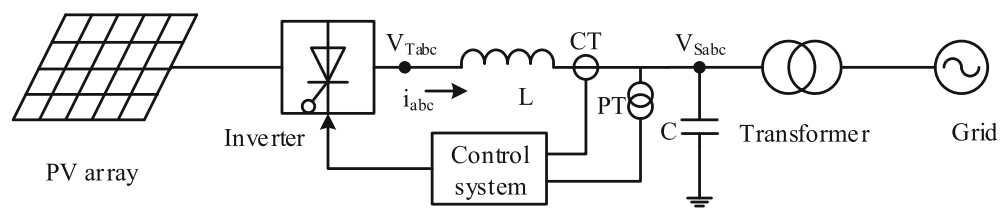

Fig. 1 Single-stage grid-connected PV system

effectiveness of control strategy for inverters under fault conditions. A brief summary is presented in the end.

\section{Modeling of inverter-based DG}

As one kind of green energy, PV generation has been widely integrated in power supply systems. Since PV generation output direct current, there must be inverters to connect it to AC grid. Therefore, PV is chosen as an example to introduce the modeling process of inverterbased DG in this study.

As shown in Fig. 1, the single-stage gird-connected PV generation system is composed of primary equipments and control system. The primary equipments include the PV array, inverter, filter inductor, filter capacitor and grid-connected transformer. The control system generates firing pulse for inverter according to specified control strategy. The PV generation system can be built based on the supporting software RSCAD in RTDS.

The commonly used constant P-Q control strategy based on dq synchronous reference frame is adopted in this study. Two different control modes are designed for different operation conditions. Under the normal conditions, DGs only have the active power output. However, during fault conditions, DGs provide extra reactive power support to mitigate the voltage sag at the PCC [13].

In Fig. 1, the relationship between output voltage and current of DC/AC converter can be expressed as:

$$
V_{\mathrm{Tabc}}=R i_{\mathrm{abc}}+L \frac{d i_{\mathrm{abc}}}{d t}+V_{\mathrm{Sabc}}
$$

The equation can be transformed into the dq synchronous reference frame:

$$
\left\{\begin{array}{l}
V_{\mathrm{Td}}=R i_{\mathrm{d}}+L \frac{d i_{\mathrm{d}}}{d t}+V_{\mathrm{Sd}}-\omega L i_{\mathrm{q}} \\
V_{\mathrm{Tq}}=R i_{\mathrm{q}}+L \frac{d i_{\mathrm{q}}}{d t}+V_{\mathrm{Sq}}+\omega L i_{\mathrm{d}}
\end{array}\right.
$$

Let the $\mathrm{d}$-axis and grid voltage vector be in the same direction in dq synchronous reference frame. The active and reactive power output of the inverter can be expressed as [14]:

$$
\left\{\begin{array}{l}
P=\frac{3}{2} u_{\mathrm{d}} i_{\mathrm{d}} \\
Q=-\frac{3}{2} u_{\mathrm{d}} i_{\mathrm{q}}
\end{array}\right.
$$

If we set $P$ and $Q$ as the active and reactive power reference, the corresponding current reference $i_{\mathrm{d}}$ and $i_{\mathrm{q}}$ under $\mathrm{dq}$ synchronous reference frame can be calculated according to (3).

In normal condition, make DG only output active power, so $i_{q}^{*}$ is 0 . But in fault conditions, current reference of q-axis will be adjusted according to the voltage sag under the constraint that output current of DG cannot exceed 1.2 times the rated value [15]:

$$
\begin{aligned}
& i_{\mathrm{q}}^{*}=\left\{\begin{array}{lc}
0, & u_{1}>0.9 \\
-2\left(1-u_{1}\right), & 0.4 \leq u_{1} \leq 0.9 \\
-1.2, & u_{1}<0.4
\end{array}\right. \\
& i_{\mathrm{d}}^{*}=\min \left(i_{\mathrm{d} 0}{ }^{*}, \sqrt{1.2^{2}-i_{\mathrm{q}}^{* 2}}\right)
\end{aligned}
$$

where $u_{1}$ is the amplitude of positive sequence voltage (p.u.) at PCC, $i_{\mathrm{do}}$ is current reference of $\mathrm{d}$-axis before the fault.

The main structure of the control system is shown in Fig. 2.

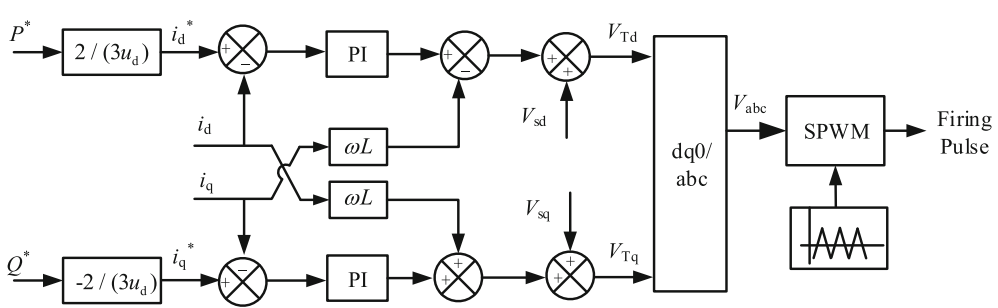

Fig. 2 Main structure of the control system 


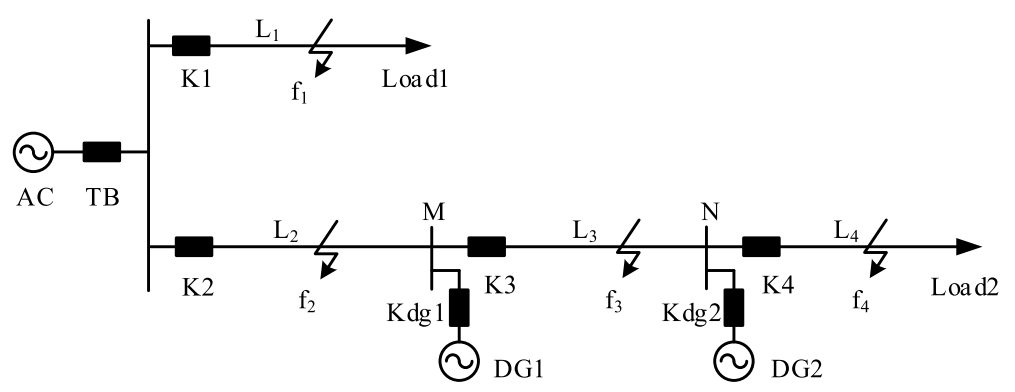

Fig. 3 A distribution network with inverter-based DGs

\section{Modeling of distribution networks with inverter-based DGs}

On the basis of Section 2, the simulation model of a neutral point ungrounded distribution network containing two inverter-based DGs, as shown in Fig. 3, can be developed.

In Fig. 3, the DG1 and DG2 represent the two single-stage grid-connected PV systems. The TB, $\mathrm{K} 1$ to $\mathrm{K} 4, \mathrm{Kdg} 1$ and $\mathrm{Kdg} 2$ are circuit breakers at different locations. The feeders in the network adopt PI model. To simulate different fault conditions, four fault locations, $\mathrm{f}_{1}$ to $\mathrm{f}_{4}$, are set at the middle of $\mathrm{L}_{1}$ to $\mathrm{L}_{4}$, respectively. Load1 and load2 are inductive loads modeled by series resistance and inductor.

The reference power for DG1 and DG2 is set to $1 \mathrm{MW}$ and $2 \mathrm{MW}$, respectively. Table 1 shows the parameters of the main components in Fig. 3.

\section{Fault simulation and calculation}

Based on the proposed simulation model in Section 3, large numbers of fault simulations are performed at different locations of the system model. The typical simulation results for three-phase faults and phase-to-phase faults at location $\mathrm{f}_{4}$ are presented in this section.

\subsection{Three-phase fault}

Set three-phase fault with $0.2 \mathrm{~s}$ duration at location $\mathrm{f}_{4}$. The current waveforms flowing through each line are shown in Fig. 4. The output current and voltage waveforms of the main source and two DGs are shown in Fig. 5.

Table 1 Parameters of main components

\begin{tabular}{ll}
\hline Components & Parameters \\
\hline Main source & Voltage magnitude: $10.5 \mathrm{kV}$ \\
& Positive impedance: $1 \angle 80^{\circ} \Omega$ \\
Transmission line $L_{1}$ to $L_{4}$ & Positive impedance: $(0.270+\mathrm{j} 0.335) \Omega / \mathrm{km}$ \\
& Length: $5 \mathrm{~km}, 4 \mathrm{~km}, 4 \mathrm{~km}, 5 \mathrm{~km}$, respectively \\
& Load1: $1 \mathrm{MVA}$, power factor is 0.9 \\
Loads & Load2: $4 \mathrm{MVA}$, power factor is 0.9 \\
\hline
\end{tabular}

From Fig. 5, it can be seen that the current supplied by main source increased greatly, while current supplied by DGs increased slightly under the fault condition, which means that the control strategy for inverter-based DGs can effectively limit the output current of DG.

\subsection{Phase-to-phase fault (A-B)}

Set A-B fault with $0.2 \mathrm{~s}$ duration at location $\mathrm{f}_{4}$. The current waveforms flowing through each line are shown in Fig. 6. The output current and voltage waveforms of the main source and two DGs are shown in Fig. 7.

From Fig. 7, it can be observed that the current of main source has the traditional fault characteristics, such as current of phase A and B increased greatly and the output current became unsymmetrical. However, fault current characteristics of DGs are obvious different. The output current increased slightly and maintained symmetrical under the A-B fault condition.

\subsection{Current and voltage phasor calculation}

In order to present the fault characteristics clearly, current and voltage phasors (steady state components under fault condition) are calculated based on one-cycle Fourier algorithm. The calculation results of the current of phase A flowing through line $\mathrm{L}_{2}, \mathrm{~L}_{3}, \mathrm{~L}_{4}$ and the voltage of phase A at PCC (M and N) are presented in this subsection.

For the three-phase fault at location $\mathrm{f}_{4}$, calculation results are as follows:

$$
\left\{\begin{array}{l}
\dot{I}_{\mathrm{L}_{2} \mathrm{~A}}=1.515 \angle-78.4^{\circ} \mathrm{kA} \\
\dot{I}_{\mathrm{L}_{3} \mathrm{~A}}=1.603 \angle-80.7^{\circ} \mathrm{kA} \\
\dot{I}_{\mathrm{L}_{4} \mathrm{~A}}=1.838 \angle-82.4^{\circ} \mathrm{kA} \\
\dot{V}_{\mathrm{MA}}=4.902 \angle-31.9^{\circ} \mathrm{kV} \\
\dot{V}_{\mathrm{NA}}=2.051 \angle-33.1^{\circ} \mathrm{kV}
\end{array}\right.
$$

Equation (5) show that due to the fault current injections from DG1 and DG2, the magnitude of $\dot{I}_{\mathrm{L}_{3} \mathrm{~A}}$ is greater than that of $\dot{I}_{\mathrm{L}_{2} \mathrm{~A}}$, while the magnitude of $\dot{I}_{\mathrm{L}_{4} \mathrm{~A}}$ is 

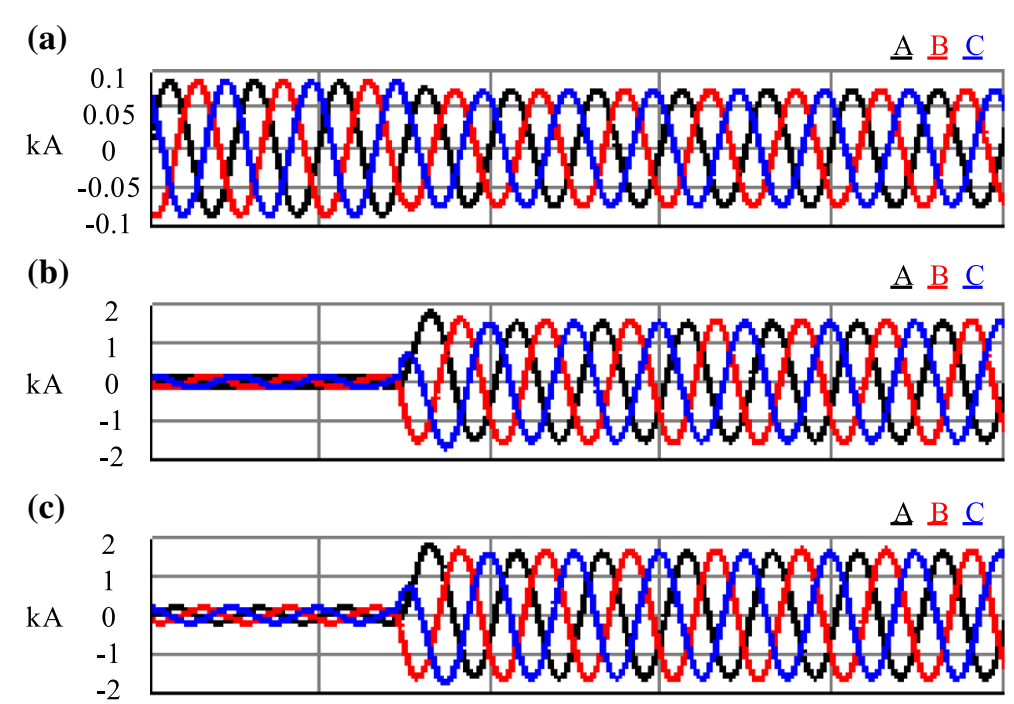

(d)

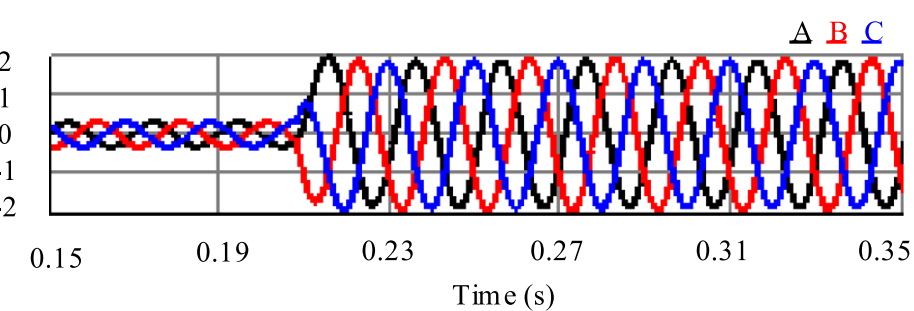

Fig. 4 Current waveforms flowing through each line for a three-phase fault at $f_{4}$. a Current through line $L_{1}$, b Current through line $L_{2}$, c Current through line $L_{3}$, d Current through line $L_{4}$

greater than that of $\dot{\dot{I}_{\mathrm{L}_{3} \mathrm{~A}}}$. The phase angle differences among $\dot{I}_{\mathrm{L}_{2} \mathrm{~A}}, \dot{I}_{\mathrm{L}_{3} \mathrm{~A}}$ and $\dot{I}_{\mathrm{L}_{4} \mathrm{~A}}$ are quite small. The magnitude of $\dot{V}_{\text {MA }}$ is greater than that of $\dot{V}_{\text {NA }}$, and $\dot{V}{ }_{\text {MA }}$ leads $\dot{V}_{\text {NA }}$ in phase angle.

For A-B fault at location $\mathrm{f}_{4}$, calculation results are as follows:

$$
\left\{\begin{array}{l}
\dot{I}_{\mathrm{L}_{2} \mathrm{~A}}=1.331 \angle-112.5^{\circ} \mathrm{kA} \\
\dot{I}_{\mathrm{L}_{3} \mathrm{~A}}=1.415 \angle-111.7^{\circ} \mathrm{kA} \\
\dot{I}_{\mathrm{L}_{4} \mathrm{~A}}=1.623 \angle-112.0^{\circ} \mathrm{kA} \\
\dot{V}_{\mathrm{MA}}=6.221 \angle-103.2^{\circ} \mathrm{kV} \\
\dot{V}_{\mathrm{NA}}=4.629 \angle-124.2^{\circ} \mathrm{kV}
\end{array}\right.
$$

It can be seen from (6) that the calculation results show the similar characteristics as the above three-phase fault results.

\section{Theoretical verification}

In this section, the theoretical derivations and calculations are presented to verify the simulation results.

\subsection{Fault equivalent circuit}

To analyze fault characteristics of distribution networks with DGs, the fault equivalent circuit should be established firstly. The output of inverter-based DG is determined by its control strategy. Under fault conditions, the PV generation can be equivalent to a current source controlled by the amplitude of positive sequence voltage at PCC according to (4):

$$
\dot{I}_{\mathrm{dg}, \mathrm{f}}=\mathrm{f}\left(u_{1}\right)
$$

where $u_{1}$ is the amplitude of positive sequence voltage at PCC and $\mathrm{f}\left(u_{1}\right)$ is a nonlinear function. For a given value of $u_{1}, \mathrm{f}\left(u_{1}\right)$ can be calculated according to (4).

For example, suppose the output current of PV is $\dot{I}_{\mathrm{dg}, \mathrm{f}}$ $=I_{\mathrm{dg}, \mathrm{f}} \angle \theta_{\mathrm{dg}}$, and the full-voltage at PCC is $\dot{U}{ }_{\mathrm{pcc}}=U_{\mathrm{pcc}} \angle$ $\theta_{\mathrm{pcc}} \cdot I_{\mathrm{dg}, \mathrm{d}}$ and $I_{\mathrm{dg}, \mathrm{q}}$ can be calculated from (4), and then $I_{\mathrm{dg}, \mathrm{f}}=\sqrt{I_{\mathrm{dg}, \mathrm{d}}{ }^{2}}+I_{\mathrm{dg}, \mathrm{q}}{ }^{2}$. Let $\Delta \theta$ be the phase angle difference between $\dot{U}_{\mathrm{pcc}}$ and $\dot{I}{ }_{\mathrm{dg}, \mathrm{f}}$, which equals to the power factor angle of PV, $\phi$. Considering (3), the angle $\phi$ can be derived from the output active and reactive power:

$$
\phi=\arctan (Q / P)=\arctan \left(-I_{\mathrm{dg}, \mathrm{q}} / I_{\mathrm{dg}, \mathrm{d}}\right)
$$

then 


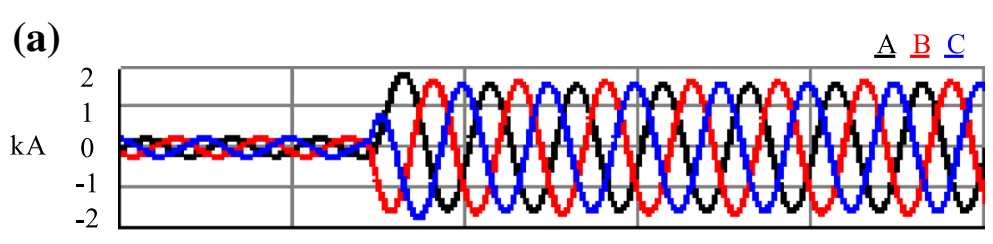

(b)

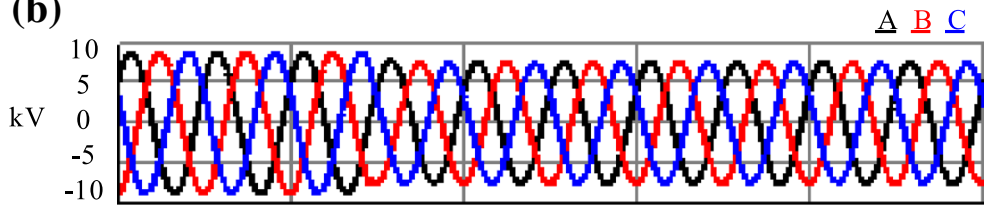

(c)

$\underline{A} \underline{B} \underline{C}$

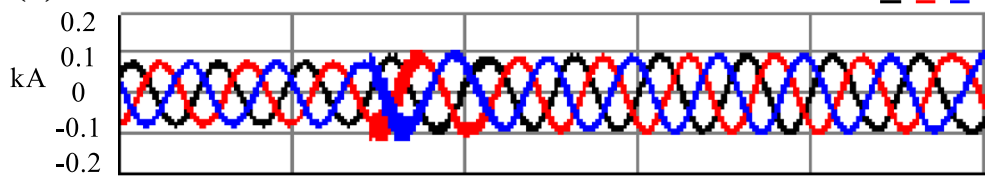

(d)

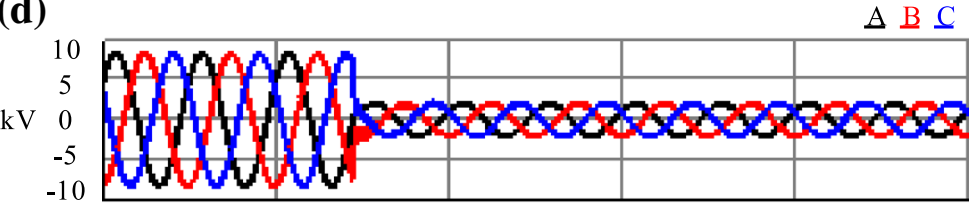

(e)

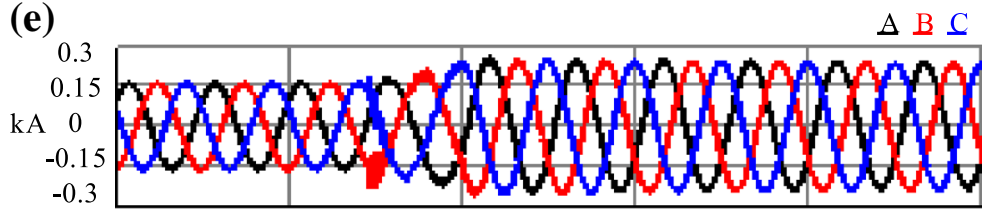

(f)

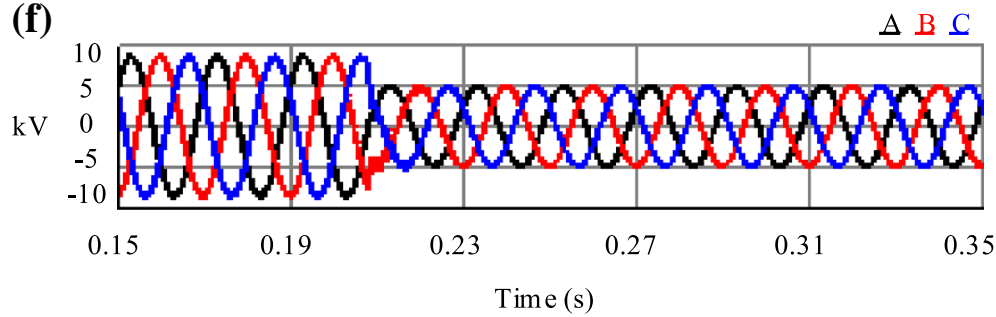

Fig. 5 Output current and voltage waveforms of each source for a three-phase fault at $\mathrm{f}_{4}$. a Output Current of main source, $\mathbf{b}$ Output voltage of main source, c Output Current of DG1, d Output voltage of DG1, e Output Current of DG2, $\mathbf{f}$ Output voltage of DG2

$$
\theta_{\mathrm{dg}}=\theta_{\mathrm{pcc}}-\phi
$$

In this paper, the fault equivalent model under $\mathrm{A}-\mathrm{B}$ fault at location $\mathrm{f}_{4}$ is taken as an example. There are positive and negative sequence components under A-B fault. The positive network contains main source and two PVs, but the negative network has no source because the main source and PV only output positive sequence voltage and current.

The positive sequence network and negative sequence network are illustrated in Fig. 8(a) and (b), respectively. Here, we suppose that each positive sequence impedance (PSI) equals its negative sequence impedance.

Where.

$\dot{E}_{\mathrm{s}}:$ Voltage of the main source;

$Z_{\mathrm{s}}$ : Equivalent PSI of the main source;

$Z_{\mathrm{L} 1}, Z_{\mathrm{L} 2}, Z_{\mathrm{L} 3}$ : PSI of $\mathrm{L}_{1}, \mathrm{~L}_{2}, \mathrm{~L}_{3}$, respectively;

$Z_{\mathrm{L} 41}$ : PSI of the line from fault point to busbar N;

$Z_{\mathrm{L} 42}$ : PSI of the line from fault point to the end of $\mathrm{L}_{4}$

$Z_{\text {Load1 }}$ : Equivalent PSI of the load1;

$Z_{\text {Load2: }}$ Equivalent PSI of the load2. 


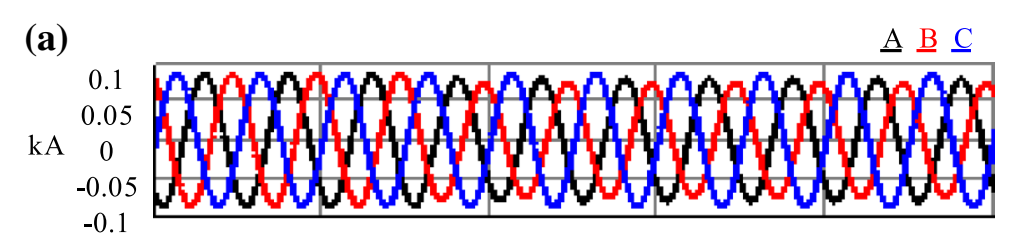

(b)

$\underline{A} \underline{B} \underline{C}$

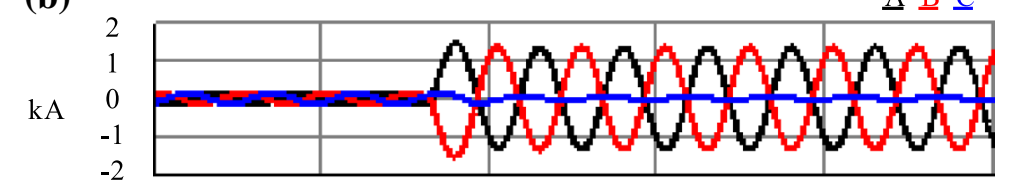

(c)

$\mathrm{A} B \mathrm{C}$

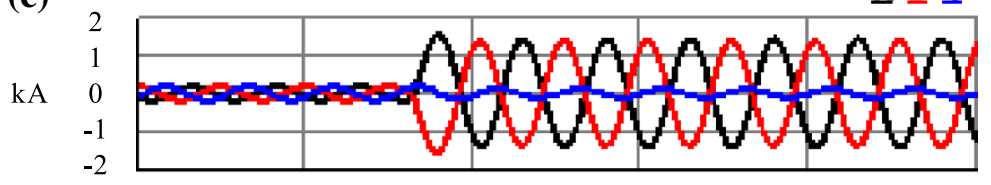

(d)

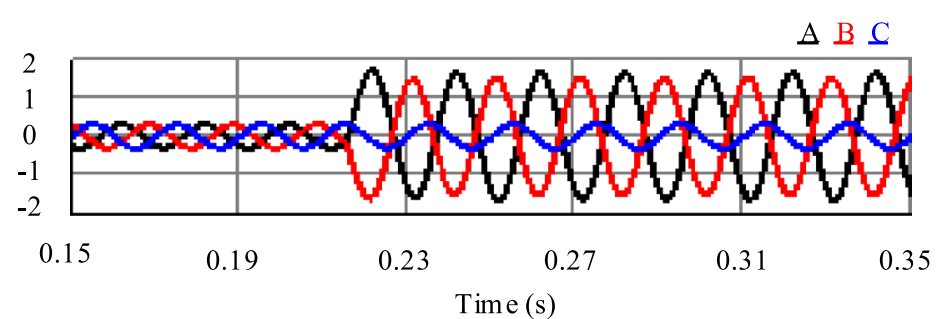

Fig. 6 Current waveforms flowing through each line for a phase A-to-phase B fault at $f_{4}$ a Current through line $L_{1}$, b Current through line $L_{2}$, c Current through line $\mathrm{L}_{3}$, d Current through line $\mathrm{L}_{4}$

The simplified positive and negative sequence networks are illustrated in Fig. 9.

In Fig. 9, the equivalent voltage source and each impedance can be expressed as:

$$
\left\{\begin{aligned}
\dot{E}_{\text {equ }, \mathrm{s}} & =k \dot{E}_{\mathrm{s}} \\
Z_{1} & =\left(Z_{\mathrm{s}} \cdot Z_{\mathrm{tem} 1}\right) /\left(Z_{\mathrm{S}}+Z_{\mathrm{tem} 1}\right)+Z_{\mathrm{L}_{2}} \\
Z_{2 \sum} & =\left(Z_{2 \sum 1} \cdot Z_{2 \sum^{2}}\right) /\left(Z_{2 \sum_{1}}+Z_{2 \sum^{2}}\right)
\end{aligned}\right.
$$

where $Z_{\text {tem } 1}=Z_{\mathrm{L} 1}+Z_{\mathrm{Load} 1}, k=Z_{\mathrm{tem} 1} /\left(Z_{\mathrm{s}}+Z_{\mathrm{tem} 1}\right), Z_{2 \Sigma 1}$ $=\left(Z_{\mathrm{s}} Z_{\mathrm{tem} 1}\right) /\left(Z_{\mathrm{s}}+Z_{\mathrm{tem} 1}\right)+Z_{\mathrm{L} 2}+Z_{\mathrm{L} 3}+Z_{\mathrm{L} 41}, \quad Z_{2 \Sigma 2}=Z_{\mathrm{L} 42}$ $+Z_{\text {Load2 }}$.

According to the boundary conditions, the compound sequence network and its simplification can be drawn in Fig. 10.

In Fig. 10(b), the equivalent impedance $Z_{2}$ and $Z_{3}$ are expressed as:

$$
Z_{2}=Z_{\mathrm{L} 3}, Z_{3}=Z_{\mathrm{L} 41}+\left(\mathrm{Z}_{2 \Sigma} \cdot \mathrm{Z}_{2 \Sigma 2}\right) /\left(\mathrm{Z}_{2 \Sigma}+\mathrm{Z}_{2 \Sigma 2}\right)
$$

\subsection{Solving method}

The mesh current method is used to analyze the simplified compound sequence network in Fig. 10(b). There are three meshes, and the corresponding mesh currents are $\dot{I}_{\mathrm{m} 1}, \dot{I}_{\mathrm{m} 2}$ and $\dot{I}_{\mathrm{m} 3}$, respectively. The three mesh current equations are as follows:

$$
\left\{\begin{array}{l}
\dot{I}_{\mathrm{m} 1} Z_{1}+\dot{U}_{\mathrm{M} 1}=\dot{E}_{\mathrm{equ}, \mathrm{s}} \\
\dot{I}_{\mathrm{m} 2} Z_{2}+\dot{U}_{\mathrm{N} 1}=\dot{U}_{\mathrm{M} 1} \\
\dot{I}_{\mathrm{m} 3} Z_{3}=\dot{U}_{\mathrm{N} 1}
\end{array}\right.
$$

Write complimentary equations by considering (7):

$$
\left\{\begin{array}{l}
\dot{I}_{\mathrm{m} 2}-\dot{I}_{\mathrm{m} 1}=\dot{I}_{\mathrm{dg} 1, \mathrm{f}}=\mathrm{f}\left(u_{\mathrm{m} 1}\right) \\
\dot{I}_{\mathrm{m} 3}-\dot{I}_{\mathrm{m} 2}=\dot{I}_{\mathrm{dg} 2, \mathrm{f}}=\mathrm{f}\left(u_{\mathrm{n} 1}\right)
\end{array}\right.
$$

There are five equations in (11) and (12) with five unknown complex variables, $\dot{I}_{\mathrm{m} 1}, \dot{I}_{\mathrm{m} 2}, \dot{I}_{\mathrm{m} 3}, \dot{U}_{\mathrm{M} 1}$ and $\dot{U}_{\mathrm{N} 1}$. Each complex variable has the real part and imaginary part. Thus, the equations can be rewritten as: 


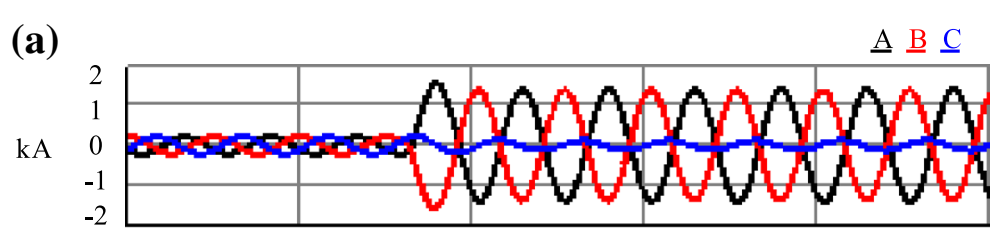

(b)

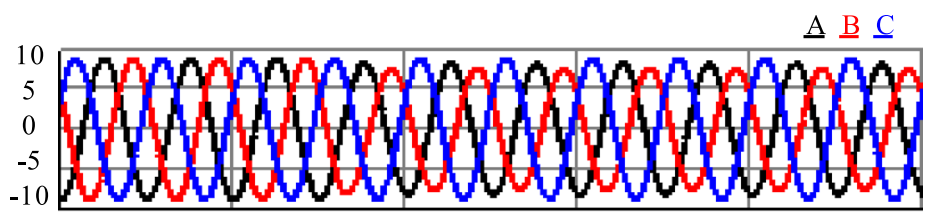

(c)

$\triangle B$ C

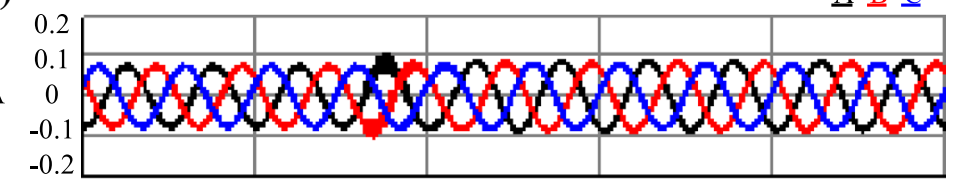

(d)

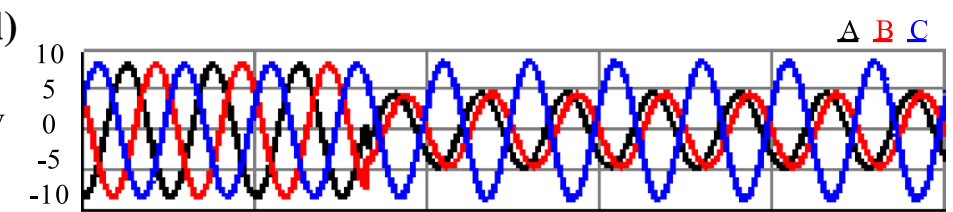

(e) 0.3

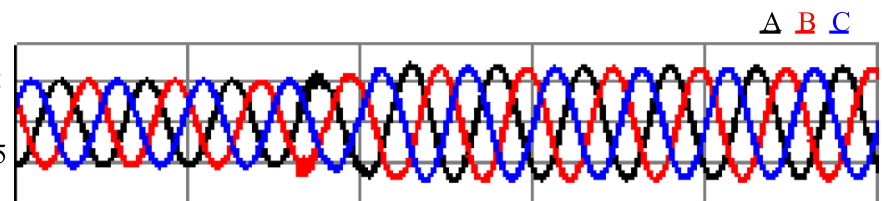

(f)

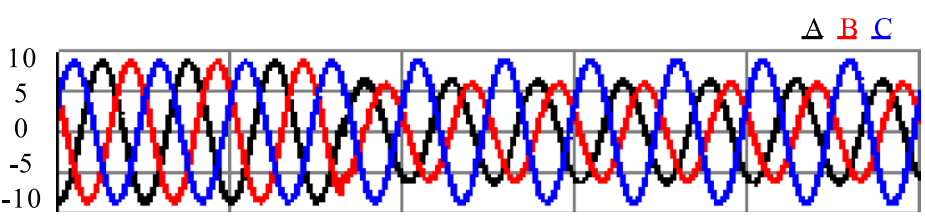

0.15

0.19

0.23

0.27

0.31

0.35

Time (s)

Fig. 7 Output current and voltage waveforms of each source for a phase A-to-phase B fault at $\mathrm{f}_{4}$. a Output Current of main source, $\mathbf{b}$ Output voltage of ma in source, c Output Current of DG1, d Output voltage of DG1, e Output Current of DG2, f Output voltage of DG2

$\left\{\begin{array}{l}\mathrm{f}_{1}=I_{\mathrm{m} 1} Z_{1} \cos \left(\theta_{\mathrm{m} 1}+\theta_{Z_{1}}\right)+U_{\mathrm{M} 1} \cos \theta_{U_{\mathrm{M} 1}}-E_{\mathrm{equ}, \mathrm{s}} \cos \theta_{E}=0 \\ \mathrm{f}_{2}=I_{\mathrm{m} 1} Z_{1} \sin \left(\theta_{\mathrm{m} 1}+\theta_{Z_{1}}\right)+U_{\mathrm{M} 1} \sin \theta_{U_{\mathrm{M} 1}}-E_{\mathrm{equ}, \mathrm{s}} \sin \theta_{E}=0 \\ \mathrm{f}_{3}=I_{\mathrm{m} 2} Z_{2} \cos \left(\theta_{\mathrm{m} 2}+\theta_{Z_{2}}\right)+U_{\mathrm{N} 1} \cos \theta_{U_{\mathrm{N} 1}}-U_{\mathrm{M} 1} \cos \theta_{U_{\mathrm{M} 1}}=0 \\ \mathrm{f}_{4}=I_{\mathrm{m} 2} Z_{2} \sin \left(\theta_{\mathrm{m} 2}+\theta_{Z_{2}}\right)+U_{\mathrm{N} 1} \sin \theta_{U_{\mathrm{N} 1}}-U_{\mathrm{M} 1} \sin \theta_{U_{\mathrm{M} 1}}=0 \\ \mathrm{f}_{5}=I_{\mathrm{m} 3} Z_{3} \cos \left(\theta_{\mathrm{m} 3}+\theta_{Z_{3}}\right)-U_{\mathrm{N} 1} \cos \theta_{U_{\mathrm{N} 1}}=0 \\ \mathrm{f}_{6}=I_{\mathrm{m} 3} Z_{3} \sin \left(\theta_{\mathrm{m} 3}+\theta_{Z_{3}}\right)-U_{\mathrm{N} 1} \sin \theta_{U_{\mathrm{N} 1}}=0 \\ \mathrm{f}_{7}=I_{\mathrm{m} 2} \cos \theta_{\mathrm{m} 2}-I_{\mathrm{m} 1} \cos \theta_{\mathrm{m} 1}-I_{\mathrm{dg} 1, \mathrm{f}} \cos \theta_{\mathrm{dg} 1}=0 \\ \mathrm{f}_{8}=I_{\mathrm{m} 2} \sin \theta_{\mathrm{m} 2}-I_{\mathrm{m} 1} \sin \theta_{\mathrm{m} 1}-I_{\mathrm{dg} 1, \mathrm{f}} \sin \theta_{\mathrm{dg} 1}=0 \\ \mathrm{f}_{9}=I_{\mathrm{m} 3} \cos \theta_{\mathrm{m} 3}-I_{\mathrm{m} 2} \cos \theta_{\mathrm{m} 2}-I_{\mathrm{dg} 2, \mathrm{f}} \cos \theta_{\mathrm{dg} 2}=0 \\ \mathrm{f}_{10}=I_{\mathrm{m} 3} \sin \theta_{\mathrm{m} 3}-I_{\mathrm{m} 2} \sin \theta_{\mathrm{m} 2}-I_{\mathrm{dg} 2, \mathrm{f}} \sin \theta_{\mathrm{dg} 2}=0\end{array}\right.$
Especially, there are four nonlinear equations related to $\mathrm{f}\left(u_{\mathrm{m} 1}\right)$ and $\mathrm{f}\left(u_{\mathrm{n} 1}\right)$. The Newton-Raphson algorithm is used to solve the equation group in (13).

During every iteration, the amplitude and phase angle of full-voltage at position $\mathrm{M}$ and $\mathrm{N}$ need to be calculated. Then $I_{\mathrm{dg} 1, \mathrm{f}}$ can be calculated according to (4) and $\theta_{\mathrm{dg} 1}$ can be calculated according to (8) and (9). $I_{\mathrm{dg} 2, \text { fand }}$ $\theta_{\mathrm{dg} 2}$ can be derived in the same way.

\subsection{Comparisons with simulation results}

For three-phase fault, the theoretical analysis results are as follows: 


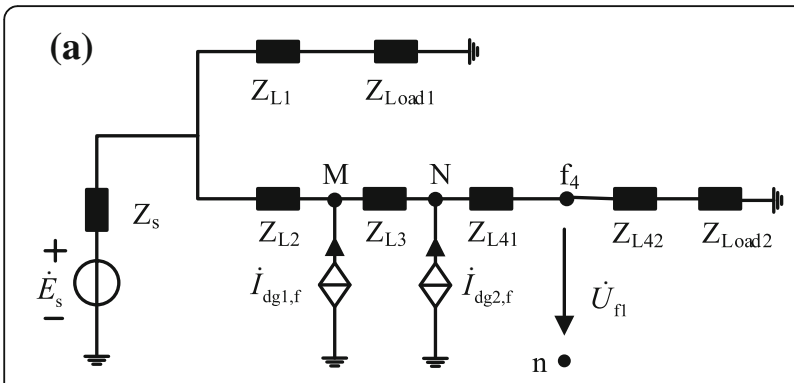

(b)

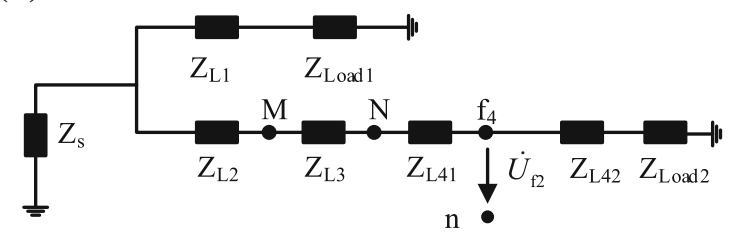

Fig. 8 Positive and negative sequence networks. a Positive sequence network, $\mathbf{b}$ Negative sequence network

$$
\left\{\begin{array}{l}
\dot{I}_{\mathrm{L}_{2} \mathrm{~A}}=1.512 \angle-82.8^{\circ} \mathrm{kA} \\
\dot{I}_{\mathrm{L}_{3} \mathrm{~A}}=1.610 \angle-82.8^{\circ} \mathrm{kA} \\
\dot{I}_{\mathrm{L}_{4} \mathrm{~A}}=1.758 \angle-87.3^{\circ} \mathrm{kA} \\
\dot{V}_{\mathrm{MA}}=4.659 \angle-33.5^{\circ} \mathrm{kV} \\
\dot{V}_{\mathrm{NA}}=1.891 \angle-36.1^{\circ} \mathrm{kV}
\end{array}\right.
$$

For A-B fault, the theoretical analysis results are as follows:

$$
\left\{\begin{array}{l}
\dot{I}_{\mathrm{L}_{2} \mathrm{~A}}=1.340 \angle-104.0^{\circ} \mathrm{kA} \\
\dot{I}_{\mathrm{L}_{3} \mathrm{~A}}=1.429 \angle-104.4^{\circ} \mathrm{kA} \\
\dot{I}_{\mathrm{L}_{4} \mathrm{~A}}=1.609 \angle-107.3^{\circ} \mathrm{kA} \\
\dot{V}_{\mathrm{MA}}=5.621 \angle-100.7^{\circ} \mathrm{kV} \\
\dot{V}_{\mathrm{NA}}=4.354 \angle-125.3^{\circ} \mathrm{kV}
\end{array}\right.
$$

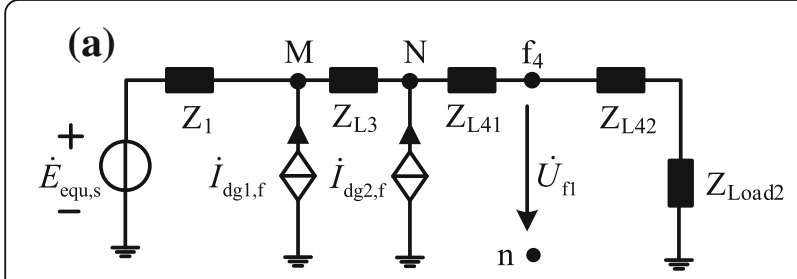

(b)

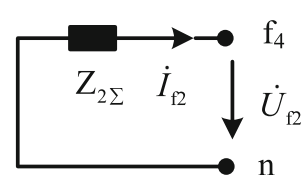

Fig. 9 Simplified sequence networks. a Simplified positive sequence network, $\mathbf{b}$ Simplified negative sequence network
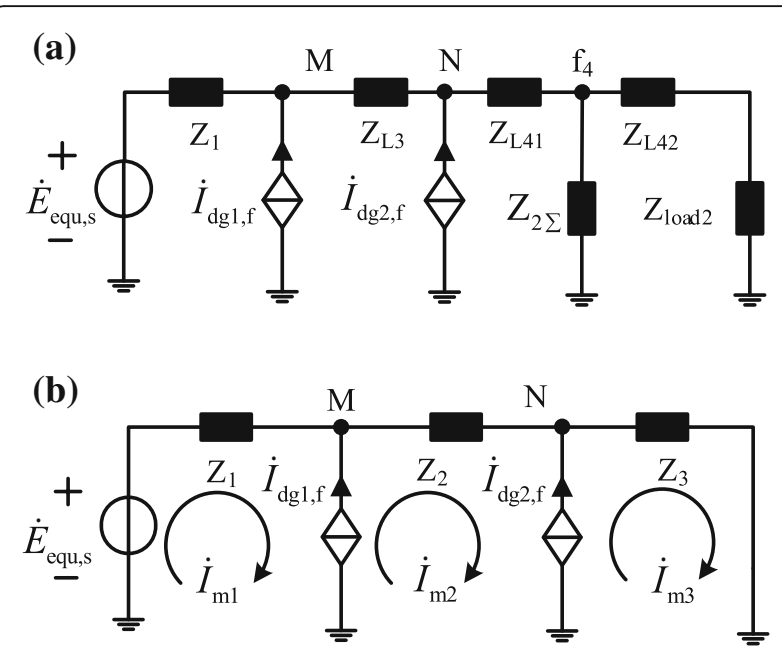

Fig. 10 Compound sequence networks. a Compound sequence network, b Simplified compound sequence network

The comparisons between simulation and theoretical results are shown in Table 2 and Table 3.

It can be seen from Table 2 and Table 3 that the theoretical results are consistent with simulation results. The relative errors of most quantities are within 5\%. All the absolute errors of phasor angles are within $5^{\circ}$ under three-phase fault condition, and within $10^{\circ}$ under $\mathrm{A}-\mathrm{B}$ fault condition. The comparisons have shown the effectiveness of the simulations results.

\section{Conclusions}

To investigate the fault characteristics of distribution networks with inverter-based DGs, this paper proposes a complete simulation model for a typical distribution network integrated with PV generators based on the RTDS.

The comparisons between the simulation results and the theoretical analysis proved the feasibility of the proposed modeling methodology. Both the fault simulation

Table 2 Comparison between simulation and theoretical results for three-phase fault at $\mathrm{f}_{4}$

\begin{tabular}{llllll}
\hline Phasors & & $\begin{array}{l}\text { Simulation } \\
\text { results }\end{array}$ & $\begin{array}{l}\text { Theoretical } \\
\text { results }\end{array}$ & $\begin{array}{l}\text { Absolute } \\
\text { errors }\end{array}$ & $\begin{array}{l}\text { Relative } \\
\text { errors } \%\end{array}$ \\
\hline$i_{\mathrm{L}_{2} \mathrm{~A}}$ & Amp. & 1.515 & 1.512 & 0.003 & 0.200 \\
& Ang. & $-78.4^{\circ}$ & $-82.8^{\circ}$ & $4.4^{\circ}$ & 2.458 \\
$i_{\mathrm{L}_{3} \mathrm{~A}}$ & Amp. & 1.603 & 1.610 & 0.008 & 0.473 \\
& Ang. & $-80.7^{\circ}$ & $-82.8^{\circ}$ & $2.1^{\circ}$ & 1.210 \\
$i_{\mathrm{L}_{4} \mathrm{~A}}$ & Amp. & 1.838 & 1.758 & 0.080 & 4.354 \\
& Ang. & $-82.4^{\circ}$ & $-87.3^{\circ}$ & $4.9^{\circ}$ & 2.689 \\
$\dot{V}_{\mathrm{MA}}$ & Amp. & 4.902 & 4.659 & 0.243 & 4.961 \\
& Ang. & $-31.9^{\circ}$ & $-33.5^{\circ}$ & $1.6^{\circ}$ & 0.928 \\
$\dot{V}_{\mathrm{NA}}$ & Amp. & 2.051 & 1.891 & 0.160 & 7.803 \\
& Ang. & $-33.1^{\circ}$ & $-36.1^{\circ}$ & $3.0^{\circ}$ & 1.675 \\
\hline
\end{tabular}

Notice: Relative error of angle is compared with $180^{\circ}$ 
Table 3 Comparison between simulation and theoretical results for A-B fault at $\mathrm{f}_{4}$

\begin{tabular}{llllll}
\hline Phasors & & $\begin{array}{l}\text { Simulation } \\
\text { result }\end{array}$ & $\begin{array}{l}\text { Theoretical } \\
\text { result }\end{array}$ & $\begin{array}{l}\text { Absolute } \\
\text { error }\end{array}$ & $\begin{array}{l}\text { Relative } \\
\text { error/\% }\end{array}$ \\
\hline$i_{\mathrm{L}_{2} \mathrm{~A}}$ & Amp. & 1.331 & 1.340 & 0.009 & 0.676 \\
& Ang. & $-112.5^{\circ}$ & $-104.0^{\circ}$ & $8.5^{\circ}$ & 4.743 \\
$i_{\mathrm{L}_{3} \mathrm{~A}}$ & Amp. & 1.415 & 1.429 & 0.014 & 0.989 \\
& Ang. & $-111.7^{\circ}$ & $-104.4^{\circ}$ & $7.3^{\circ}$ & 4.138 \\
$i_{\mathrm{L}_{4} \mathrm{~A}}$ & Amp. & 1.623 & 1.609 & 0.014 & 0.863 \\
& Ang. & $-112.0^{\circ}$ & $-107.3^{\circ}$ & $4.7^{\circ}$ & 2.578 \\
$\dot{V}_{\mathrm{MA}}$ & Amp. & 6.221 & 5.621 & 0.599 & 9.629 \\
& Ang. & $-103.2^{\circ}$ & $-100.7^{\circ}$ & $2.5^{\circ}$ & 1.369 \\
$\dot{V}_{\text {NA }}$ & Amp. & 4.629 & 4.354 & 0.276 & 5.962 \\
& Ang. & $-124.2^{\circ}$ & $-125.3^{\circ}$ & $1.1^{\circ}$ & 0.637 \\
\hline
\end{tabular}

Notice: Relative error of angle is compared with 180

waveforms and the phasor calculation results show that the output current of inverter-based DG increases slightly (less than 2 times of rated value) and maintains symmetrical under different fault conditions, which are quite different from that of traditional sources.

Moreover, using the proposed simulation model, RTDS can produce analogue voltage and current signals reflecting fault characteristics of distribution network with inverterbased DGs. Then these analogue signals can be used to test actual protection devices in a close- loop manner.

\section{Acknowledgments}

This work was supported by Nation Natural Science Foundation of China (51377100) and the Key Scientific and Technological Project of State Grid Shandong Power Company (SGSDWF00YJJS1400563).

\section{Authors' contributions}

LW investigated the modeling methodology of distribution networks integrated with IBDGs, conducted the fault simulation and drafted the manuscript. HG proposed the equivalent circuit of distribution networks with IBDGs and the solution method for loop current. GZ verified the simulation model and analyzed the simulation results. All authors read and approved the final manuscript.

\section{Authors' information}

Longchang Wang was born in Shandong Province, China, in 1990. He received the B.S. degree in electrical engineering from Shandong University, Jinan, China, in 2014. He is now a Master candidate in the School of Electrical Engineering, Shandong University. His research interest is power system protection and control. E-mail:longchangw@126.com.

Houlei Gao (M'11) was born in Shandong Province, China, in 1963. He received the B.S. and M.S. degrees in electrical power engineering from Shandong University of Technology, Jinan, China, in 1983 and 1988, respectively, and the Ph.D. degree in electrical power system and automation from Tianjin University, Tianjin, China, in 1997. From 2004 to 2005, he worked as senior visiting scholar with the School of Electrical and Electronic Engineering, Queen's University Belfast, U.K. He is currently a Professor at the School of Electrical Engineering, Shandong University, China. He has authored or coauthored more than 170 technical papers. His research interests include power system protection, fault location, smart substation and distributed generation. E-mail: houleig@sdu.edu.cn. Guibin Zou (M'12) was born in Shandong Province, China, in 1971. He received the M.Sc. and Ph.D. degrees in the automation of electric power systems from Shandong University, Jinan, China, in 2000 and 2009, respectively. Currently, he is a Professor with the School of Electrical Engineering, Shandong University. His research areas include power system protection and control, power system simulation and modeling, digital substations, and wind power generation techniques.

\section{Competing interests}

The authors declare that they have no competing interests.

Received: 23 January 2017 Accepted: 29 June 2017

Published online: 15 August 2017

\section{References}

1. Gia Ing, K., Jamian, J. J., Mokhlis, H., \& Illias, H. A. (2016). Optimum distribution network operation considering distributed generation mode of operations and safety margin. IET Renew Power Gener, 10(8), 1049-1058, 9.

2. Adefarati, T., \& Bansal, R. C. (2016). Integration of renewable distributed generators into the distribution system: A review. IET Renew Power Gener, 10(7), 873-884, 7.

3. Degefa, M. Z., Alahäivälä, A., Kilkki, O., et al. (Nov. 2016). MAS-based modeling of active distribution network: The simulation of emerging behaviors. IEEE Trans Smart Grid, 7(6), 2615-2623.

4. Haj-ahmed, M. A., \& Illindala, M. S. (July-Aug. 2014). The influence of inverter-based DGs and their controllers on distribution network protection. IEEE Trans Ind Appl, 50(4), 2928-2937.

5. Houlei Gao, Juan Li and Bingyin Xu, "Principle and implementation of current differential protection in distribution networks with high penetration of DGs," IEEE Trans Power Delivery, vol. PP, no.99, pp.1-1. doi: 10.1109/TPWRD.2016.2628777.

6. Sharma, A., Srivastava, S. C., \& Chakrabarti, S. (May 2016). Testing and validation of power system dynamic state estimators using real time digital Simulator (RTDS). IEEE Trans Power Syst, 31(3), 2338-2347.

7. AL-Ismail, F. S., Hassan, M. A., \& Abido, M. A. (2014). RTDS implementation of STATCOM-based power system stabilizers. Can J Electr Comput Eng, 37(1), 48-56, winter.

8. S. R. Lee, J. Y. Yoon, J. H. Kim, et al, "Protective relay tests of hybrid SFCLs in a Korean distribution power system using RTDS," IEEE Trans Appl Supercond, vol. 21, no. 3, pp. 2188-2192, June 2011.

9. Wang, B., Dong, X., Bo, Z., \& Perks, A. (2008). RTDS environment development of ultra-high-voltage power system and relay protection test. IEEE Trans Power Delivery, 23(2), 618-623.

10. Juan, L., Gao, H., \& Zhu, G. (2016). Inverse-time current differential protection in active distribution network considering characteristics of inverter-interfaced distributed generations. Trans China Electrotechnical Society, 31(17), 74-83.

11. Jingliao, S., Yongli, L., Shengwei, L., et al. (2009). Study on adaptive current instantaneous trip protection scheme for distribution network with inverter interfaced DG. Automation of Electric Power Systems, 33(14), 71-76.

12. Wu, Z., Wang, G., Haifeng, L., et al. (2013). Analysis on the distribution network with distributed generators under phase-to-phase short-circuit faults. Proceedings of the CSEE, 33(1), 130-136.

13. L. Wang, H. Gao, J. Wang, et al, "Modeling and fault simulation of active distribution network based on RTDS", 2016 China International Conference on Electricity Distribution (CICED), Xi'an, 2016, pp. 1-5.

14. Xi, C. (2013). Develop of three-phase PV grid inverter and research of grid control strategy. China: Shandong University.

15. Kong, X., Zhe, Z., Xianggen, Y., et al. (Dec.2013). Study on fault current characteristics and fault anal-ysis method of power grid with inverter interfaced distributed generation. Proceedings of CSEE, 33(34), 65-74.

\section{Submit your manuscript to a SpringerOpen ${ }^{\mathcal{O}}$ journal and benefit from:}

- Convenient online submission

Rigorous peer review

- Open access: articles freely available online

- High visibility within the field

- Retaining the copyright to your article

Submit your next manuscript at $>$ springeropen.com 